\title{
Studies on the Effects of L-Thyroxine, L-Carnitine and an L-Thyroxine-L-Carnitine Combination on Dipalmitoyl Phosphatidylcholine Content and on Phosphatidylcholine Species Composition in Fetal Rat Lungs
}

\author{
ALFHRED LOHNINGER, HANS-PETER KRIEGLSTEINER, HEINRICH SALZER, \\ WOLFGANG ERHARDT, WOLFGANG EPPL, AND ERICH KAISER
}

\begin{abstract}
Department of Medical Chemistry and First Department of Obstetrics and Gynecology, University of Vienna, Vienna, Austria, Department of Obstetrics and Gynecology, Malteser Clinic, Bonn, and Institute of Experimental Surgery, Technical University of Munich, Munich, Federal Republic of Germany
\end{abstract}

\begin{abstract}
The aim of the present study was to examine the effects of maternal carnitine treatment combined with thyroxine, a hormone influencing both lung maturation and carnitine metabolism. Administration of a carnitine-thyroxine combination to pregnant rats resulted in a significant increase of DPPC content in fetal rat lungs to $8.8 \pm 1.8$ $\mathrm{mg} / \mathrm{g}$ dry weight (mean $\pm \mathrm{SD}$ ), compared with the control group, the carnitine-treated group, and the thyroxinetreated group $[5.4 \pm 1.8(p<0.01), 5.6 \pm 1.5(p<0.01)$, and $6.6 \pm 1.0 \mathrm{mg} / \mathrm{g}$ dry weight, respectively]. The portion of DPPC in the PC species increased significantly from $20.9 \pm 2.1 \%$ in the control group and to $27.2 \pm 3.5 \%(p<$ $0.01)$ in the carnitine-thyroxine combination group. A significant $(p<0.01)$ diminution of the palmitoyl-palmitoleyl PC (16:0/16:1-PC) portion in the PC species was found. Maternal carnitine administration resulted in an elevation of the carnitine levels in the fetal lungs to approximately twice those of the controls $(p<0.01)$. The combined adminstrration of carnitine and thyroxine resulted in no increase in the total carnitine content but in a significant $(p<0.01)$ increase of the short chain acylcarnitine content. The present results demonstrate that carnitine potentiates the effects of thyroxine on DPPC content and support the concept of an interrelationship between carnitine and thyroxine metabolism. (Pediatr Res 20: 1280-1283, 1986)
\end{abstract}

\section{Abbreviations}

PC, phosphatidylcholine

$P C$ 30, 30 carbon atoms in acyl radicals PC 32, 32 carbon atoms in acyl radicals PC 34, 34 carbon atoms in acyl radicals PC 36, 36 carbon atoms in acyl radicals PC 38, 38 carbon atoms in acyl radicals 16:0/16:1 PC, palmitoyl-palmitoleyl PC 16:1/16:0 PC, palmitoleyl-palmitoyl PC DPPC, dipalmitoyl PC

Received February 6, 1986; accepted July 22, 1986

Reprint requests Alfred Lohninger, Institute for Medical Chemistry, University of Vienna, Währingerstrasse 10, A-1090 Vienna, Austria

This work was supported by grants from the Medical Scientific Foundation of the Mayor of Vienna, Austria, and by grants from the Allianz Insurance Company, FRG.
It is well established that glucocorticoids accelerate maturation of the fetal lung in animals and decrease the incidence of respiratory distress syndrome in human infants. Since glucocorticoids are not completely effective in preventing respiratory distress syndrome in human infants (1), there was current interest in the use of other agents (2). Several studies have indicated that thyroid hormones have similar influences on lung differentiation $(3,4)$. Effects of glucocorticoids and thyroid hormones were more than additive (5), suggesting different mechanisms of actions.

We have shown that carnitine, like betamethasone, influenced the DPPC content in fetal rat lungs (6), likely via two dissimilar mechanisms. In addition, we found that maternal administration of a carnitine-betamethasone combination resulted in a significant increase in DPPC content of fetal rat lungs in comparison with untreated controls and with animals treated with carnitine or betamethasone alone (7).

Carnitine, 3-hydroxy-4-trimethylaminobutyrate, is essential in lipid metabolism. The most important function of carnitine is the transport of long chain fatty acids across the inner mitochondrial membrane (8). Thyroid hormone influences carnitine metabolism (9) and accelerates mitochondrial fatty acid oxidation by effects on carnitine palmitoyltransferase (10).

The aim of the present study was to examine the effects of maternal carnitine treatment combined with thyroxine, a hormone influencing both lung maturation and carnitine metabolism.

The amount of surfactant stored in alveolar type II cells is crucial for the survival of premature babies. DPPC is the principal component of the lung surfactant complex and is mainly responsible for its surface active properties (2). Thus to evaluate the effects of the different maternal treatments we determined both DPPC content and the portion of DPPC in total PC in fetal rat lungs.

\section{MATERIALS AND METHODS}

Ninety-six female Wistar rats of stock $\mathrm{Ch}$ bb-Thom with an average weight of $300 \mathrm{~g}$ and an expected gestation period of 23 days were randomized and divided into eight groups, four groups reported here, four groups reported elsewhere (7). The gestational age was known within $24 \mathrm{~h}$. The rats were treated intraperitoneally from day 16 to day 19 of gestation according to the schedule shown in Table 1.

Preparation of lung tissue. Immediately after delivery of the 
fetuses on gestational day 20 by caesarean section, the fetal trachea was clamped before spontaneous inspiration could occur. The chests of the fetuses were opened by means of parasternal incision. The fetal lungs were then grouped according to litter to preclude station-related differences. The fetal lungs were homogenized, extracted, and washed using the method of Folch et al. (11).

Phospholipid analysis. The main phospholipid classes were separated as bands by thin-layer chromatography using the solvent system chloroform/methanol/1\% potassium chloride solution (43/47/4, v/v/v) (6). 1,2 Dipalmitoyl-sn-glycero-3-phosphocholine and the glycero-3-phosphocholine species composition were assayed as the corresponding diacylglycerol trimethylsilylether derivatives by gas-liquid chromatography with glass capillary columns (12).

Carnitine assay. The tissue was flash-frozen immediately after removal. The perchloric acid extracts were used for assaying free and short chain acylcarnitine. The carnitine esters were saponified and assayed as free carnitine by radioenzymatic means (13), with two modifications: HEPES instead of TRIS buffer (14) and $N$-ethyl-maleimide instead of tetrathionate (15).

Chemicals. "L-Carnitin-Leopold" was obtained from Leopold Ltd. (Graz, Austria). Chloroform, methanol, pyridine, hexamethyldisilazane, thin-layer chromatography plates (silica gel 60), and HEPES were obtained from E. Merck (Darmstadt, FRG). Bacillus cereus-derived phospholipase $\mathrm{C}$ and carnitine acetyltransferase were obtained from Boehringer-Mannheim (Mannheim, FRG). Labeled acetyl coenzyme A was obtained from New England Nuclear (Boston, MA). $N$-Ethylmaleimide and dimyristoyl-sn-glycero-3-phosphocholine were supplied by Sigma Chemical Co. (St. Louis, MO).

Statistical comparisons between the different groups were made using analysis of variance followed by Dunnet's $t$ test for multiple comparison (16).

\section{RESULTS}

Only small differences of the total phospholipid content in the fetal rat lungs were found in the different treatment groups (data not shown).

$D P P C$. The combined administration of thyroxine and carnitine resulted in a marked increase in the DPPC content in comparison with the control group $(p<0.01)$, the carnitinetreated group $(p<0.01)$, and the thyroxine-treated group. A moderate response was noted after thyroxine, and no response was noted after carnitine treatment alone (Table 2).

Table 1. Treatment schedule

\begin{tabular}{lccc}
\hline \multicolumn{1}{c}{$\begin{array}{c}\text { Experimental } \\
\text { group }\end{array}$} & $\begin{array}{c}\text { Solute } \\
(\mathrm{ml} / \text { day })\end{array}$ & $\begin{array}{c}\text { L-Thyroxine } \\
(\mathrm{mg} / \mathrm{kg})\end{array}$ & $\begin{array}{c}\text { L-Carnitine } \\
(\mathrm{mg} / \mathrm{kg})\end{array}$ \\
\hline $\begin{array}{l}\text { Controls } \\
\text { Carnitine }\end{array}$ & $1 \mathrm{NaCl}$ & & \\
Thyroxine & $1 \mathrm{H}_{2} \mathrm{O}$ & & 20.0 \\
Thyroxine + carnitine & $1 \mathrm{H}_{2} \mathrm{O}$ & 0.15 & \\
\hline
\end{tabular}

The portion of DPPC in the PC species in the fetal rat lungs exhibited a significant rise $(p<0.01)$ in the thyroxine-carnitine combination group. Only a moderate increase after maternal thyroxine or carnitine treatment was noted (Table 2).

PC 32 monoenic species. The PC 32 monoenic species can be characterized as palmitoyl-palmitoleyl PC (16:0/16:1 PC) and palmitoleyl-palmitoyl PC (16:1/16:0 PC) (6).

The portion of palmitoyl-palmitoleyl PC in total PC decreased significantly $(p<0.01)$ after the combined administration of thyroxine and carnitine in comparison with the control value. This decrease was less pronounced after administration of carnitine or thyroxine alone (Table 2).

After thyroxine treatment a significant increase $(p<0.01)$ of the palmitoleyl-palmitoyl PC portion in total PC was found compared with the control group. This increase was less pronounced after the combined administration of carnitine and thyroxine.

Phosphatidylcholine species composition. In most methods commonly used for determination of surfactant PC, disaturated PC consisting of DPPC and palmitoyl-myristoyl PC is determined.

Both maternal carnitine and thyroxine treatment failed to increase the portion of palmitoyl-myristoyl PC in total PC (Table 3 ). But there is a pronounced increase of the PC 32 portion in total PC, obviously an additive effect of the increase of the two PC 32 species, DPPC and palmitoleyl-palmitoyl PC (Table 2). Also, maternal administration of the carnitine-thyroxine combination resulted in a significant $(p<0.01)$ increase of the PC 32 portion in total PC (Table 3 ). This time, however, the PC 32 increase is due mainly to the significant $(p<0.01)$ increase of the DPPC portion.

Generally, the increase of the PC 32 portion in the treated groups was mainly compensated by a decrease of the PC 34 portion in the PC species (Table 3).

Carnitine. Figure 1 shows the content of total carnitine and short chain acylcarnitine in the fetal lungs. Maternal carnitine administration $(20 \mathrm{mg} / \mathrm{kg})$ caused a significant increase $(p<$ 0.01 ) in the total carnitine content and short chain acylcarnitine content. Thyroxine failed to influence the carnitine content. Unexpectedly, the combined administration of carnitine and thyroxine resulted in no increase of total carnitine content but in a striking increase $(p<0.01)$ of short chain acylcarnitine content in the fetal lungs. Obviously, the sole increase of short chain acylcarnitine is specific for the combination.

Fetal weight and fetal lung weight. Both carnitine and thyroxine treatment resulted in an increase of fetal weight compared with controls (Table 4). After carnitine treatment there was a significant $(p<0.01)$ increase of the fetal lung weight, compared with control and carnitine-thyroxine combination group. Also thyroxine treatment resulted in a marked increase (Table 4). Since the ratio of lung dry weight:wet weight was similar in the different groups, it can be excluded that the weight gain after the carnitine or thyroxine treatment was due to the development of edema. Also, the average litter size in the different groups was similar. Interestingly, after maternal administration of the car-

Table 2. PC-32 species in fetal rat lungs*

\begin{tabular}{|c|c|c|c|c|c|}
\hline \multirow[b]{2}{*}{ Treatment } & \multirow[b]{2}{*}{$n$} & \multirow{2}{*}{$\begin{array}{c}\text { DPPC } \\
(\mathrm{mg} / \mathrm{g} \text { dry } w t)\end{array}$} & \multicolumn{3}{|c|}{$\% \mathrm{PC}-32$ species in total $\mathrm{PC}$} \\
\hline & & & DPPC & $16: 0 / 16: 1-\mathrm{PC} \dagger$ & $16: 1 / 16: 0-\mathrm{PC}+$ \\
\hline $\mathrm{NaCl}$ (controls) & 16 & $5.4 \pm 1.8$ & $20.9 \pm 2.1$ & $4.2 \pm 1.1$ & $8.4 \pm 1.6$ \\
\hline Carnitine & 6 & $5.6 \pm 1.5$ & $22.6 \pm 5.0$ & $3.7 \pm 1.1$ & $10.9 \pm 4.3$ \\
\hline Thyroxine & 9 & $6.6 \pm 1.0$ & $22.9 \pm 2.8$ & $3.5 \pm 0.5$ & $10.8 \pm 2.9 \ddagger$ \\
\hline Thyroxine + carnitine & 6 & $8.8 \pm 1.8 \div \S$ & $27.2 \pm 3.5 \ddagger$ & $2.8 \pm 0.4 \ddagger$ & $9.8 \pm 2.1$ \\
\hline
\end{tabular}

* Values are means $\pm \mathrm{SD} ; n$, number of experiments (PC-32, total carbon atoms in acyl radicals is 32 ).

$\uparrow$ 16:0/16:1-PC, palmitoyl-palmitoleyl PC (16:1/16:0-PC, palmitoleyl-palmitoyl PC).

$\ddagger$ Significantly higher (lower) $(p<0.01)$ compared with control values.

$\S$ Significantly higher $(p<0.01)$ compared with value of carnitine-treated group. 
Table 3. PC species (percentage of total PC)*

\begin{tabular}{lrrllcc}
\hline \multicolumn{1}{c}{ Treatment } & $n$ & PC-30 $\dagger$ & PC-32 $\dagger$ & PC- $34 \dagger$ & PC-36 $\dagger$ & PC-38 $\dagger$ \\
\hline NaCl (controls) & 16 & $7.1 \pm 2.5$ & $33.5 \pm 3.3$ & $33.7 \pm 2.8$ & $19.2 \pm 2.6$ & $6.3 \pm 1.5$ \\
Carnitine & 6 & $7.2 \pm 1.6$ & $37.1 \pm 8.4 \ddagger$ & $30.8 \pm 2.9 \S$ & $17.4 \pm 1.3$ & $7.2 \pm 4.8$ \\
Thyroxine & 9 & $6.4 \pm 1.6$ & $36.8 \pm 4.9$ & $30.1 \pm 3.0$ & $16.9 \pm 2.4$ & $9.7 \pm 2.8 \|$ \\
Thyroxine + carnitine & 6 & $6.9 \pm 1.9$ & $39.8 \pm 5.6 \ddagger$ & $26.9 \pm 1.9 \rrbracket$ & $17.6 \pm 3.2$ & $8.7 \pm 2.5$ \\
\hline
\end{tabular}

* Values are means $\pm \mathrm{SD} ; n$, number of experiments.

$\dagger$ PC-30 $(32,34,36,38)$, sum of carbon atoms in the acyl radicals is $30(32,34,36,38)$.

$\ddagger$ Significantly higher $(p<0.01)$ compared with control.

$\S$ Significantly lower $(p<0.05)$ compared with control.

$\|$ Significantly higher $(p<0.05)$ with control.

I Significantly lower $(p<0.01)$ compared with control.
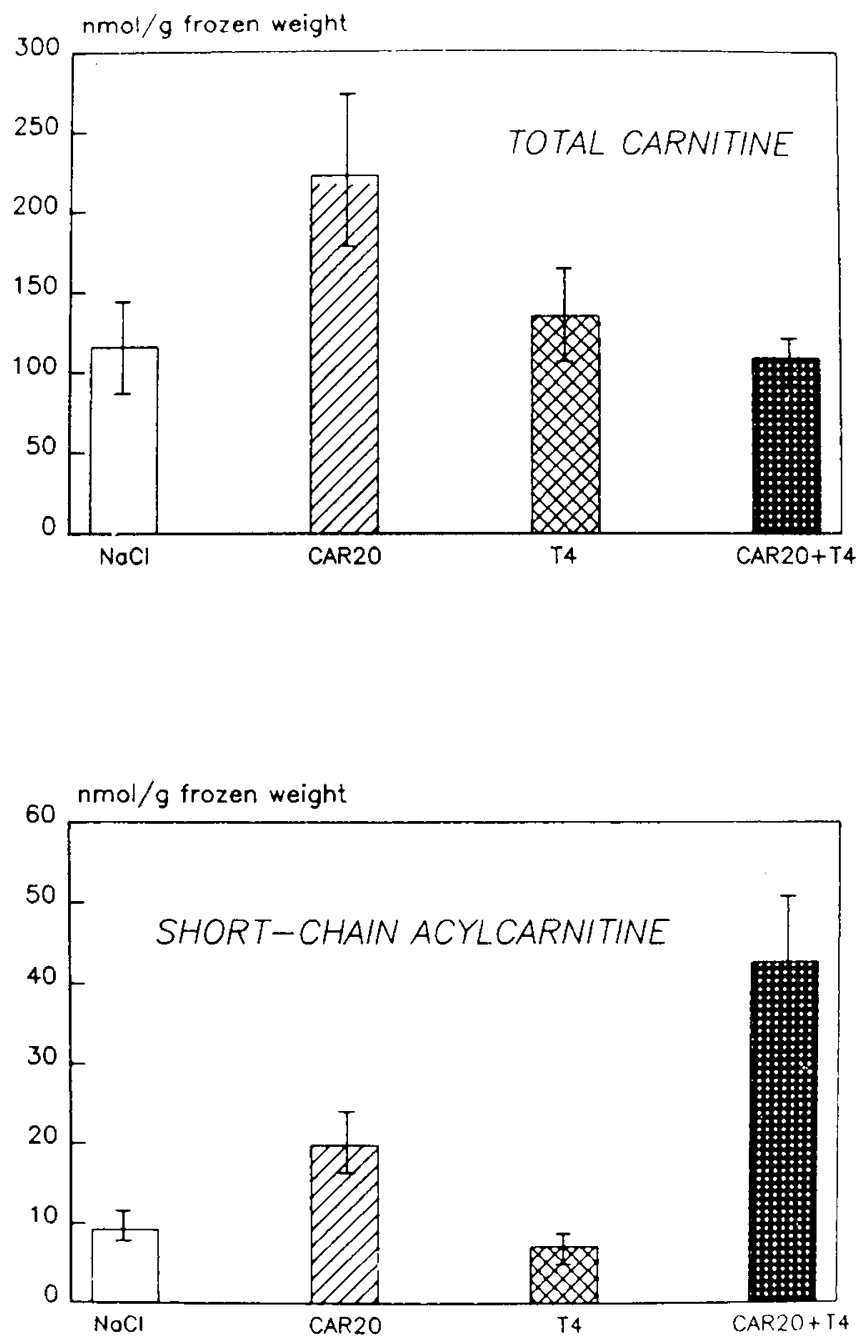

Fig. 1. L-Carnitine content (in $\mathrm{nmol} / \mathrm{g}$ frozen wt) of fetal rat lungs after maternal L-thyroxine $\left(\mathrm{T}_{4}\right)(n=9)$, L-carnitine (CAR 20) $(n=6)$, and L-thyroxine-L-carnitine (CAR $\left.20+\mathrm{T}_{4}\right)(n=6)$ treatments in comparison with control group ( $\mathrm{NaCl})(n=16)$. Bars, mean $\pm \mathrm{SD}$ in each group. Total carnitine: CAR 20 value is significantly $(p<0.01)$ higher compared with those of $\mathrm{NaCl}, \mathrm{T}_{4}$, and CAR $20+\mathrm{T}_{4}$. Short-chain acylcarnitine: The CAR 20 value is significantly higher $(p<0.01)$ compared with those of $\mathrm{NaCl}$ and $\mathrm{T}_{4}$; the CAR $20+\mathrm{T}_{4}$ value is significantly higher $(p<0.001)$ compared with all other groups.

nitine-thyroxine combination there was a moderate decrease of both fetal weight and fetal lung weight in comparison with control animals (Table 4).

\section{DISCUSSION}

Weinhold et al. (17) have shown that $50-60 \%$ of fetal rats delivered 2 days prematurely survive when placed in an incuba-
Table 4. Body and lung wt of fetal rats*

\begin{tabular}{lrcl}
\hline \multicolumn{1}{c}{ Treatment } & \multicolumn{1}{c}{$n$} & $\begin{array}{c}\text { Body wt } \\
(\mathrm{g})\end{array}$ & \multicolumn{1}{c}{$\begin{array}{c}\text { Lung wt } \\
(\mathrm{mg})\end{array}$} \\
\hline $\mathrm{NaCl}$ (controls) & 17 & $3.0 \pm 0.6$ & $58.2 \pm 12.9$ \\
Carnitine & 6 & $3.3 \pm 0.8$ & $78.0 \pm 26.7 \dagger$ \\
Thyroxine & 10 & $3.4 \pm 0.7$ & $72.0 \pm 15.5$ \\
Thyroxine + carnitine & 6 & $2.7 \pm 0.5$ & $51.9 \pm 5.2$ \\
\hline
\end{tabular}

$*$ Values are means $\pm \mathrm{SD} ; n$, number of experiments.

$\uparrow$ Significantly higher $(p<0.01)$ compared with control and thyroxine + carnitine-treated groups.

tor, whereas fetuses delivered 3 days before term did not survive. In the present study the fetal rats were delivered 3 days before term, in contrast to previous studies in which delivery was performed 2 days prematurely (6).

Thyroid hormone was found to accelerate fetal lung maturation in several mammalian species. The role of endogenous thyroid hormones in pulmonary surfactant maturation is not clearly established. Some clinical studies found lower concentrations of thyroxine, triiodothyronine, and thyrotropin releasing hormone in cord serum of infants who subsequently developed respiratory distress syndrome (18-20).

Human (21) and rat placentas (22) are active sites of inner ring deiodination of thyroxine and triiodothyronine, converting these active thyroid hormones into the inactive iodothyronines, reversing triiodothyronine from thyroxine and 3,3'-diiodothyronine, and reversing $3^{\prime}$-monoiodothyronine from triiodothyronine. Dussault and Coulombe (23) reported a minimal placental transfer of thyroxine in the rat. They assumed from their data, and from the fact that rats are hypothyroid at birth, an autonomous development of the hypothalamic-pituitary-thyroid axis. Conversely, Gross et al. (5) found that maternal administration of triiodothyronine increased PC synthesis in fetal rat lungs. In the present experiments, administration of thyroxine to pregnant rats produced an enhancement of the DPPC content (Table 2) and changes of the PC species composition in fetal lungs (Table 3). These observations suggest that thyroxine and triiodothyronine cross the rat placenta to some extent. Nuclear receptors for thyroid hormones, particularly triiodothyronine receptors, have been detected in the developing rat lung (24) and fetal human lung (25).

As discussed in detail $(6,7)$, L-carnitine produces no toxic side effects. It is important in fatty acid oxidation by mitochondria and has several additional functions in cell metabolism.

Carnitine metabolism of the human fetus resembles that of rat fetus in many aspects. 1) In human and rat fetuses, the rate of carnitine synthesis is low (26). 2) In human and rat fetuses and neonates, plasma and tissue carnitine levels are low and increase after birth (27-29). 3) Carnitine is essential for fatty acid oxidation and subsequently for ketogenesis (30).

Administration of carnitine to pregnant rats elevated both free carnitine and short chain acylcarnitine levels in the fetal rat lungs (Fig. 1). Supposedly this increase is accompanied by an enhanced rate of fatty acid oxidation. Obviously, an effect of maternal carnitine administration on the fetal lung DPPC content depends 
on the maturity of the fetal lungs, since, in contrast to the present results, we found an increase of the DPPC content after maternal carnitine administration in older fetuses (delivered on gestational day 21) (6).

The combined administration of carnitine and thyroxine to pregnant rats resulted in a striking, highly significant $(p<0.01)$ increase of the DPPC content in the fetal lungs, compared with control and solely carnitine-treated or thyroxine-treated animals.

The alveolar type II cell is the source of surfactant within the lung (2). Compared with lung tissue, isolated alveolar type II cells are enriched in disaturated PC (31), and only alveolar type II cells exhibited marked cellular changes correlating with varying thyroxine concentrations (32).

An accelerated differentiation of alveolar type II cells by thyroxine and an acceleration of lipid metabolism induced by thyroxine and by carnitine could be the basis for the increased DPPC content in fetal lungs. Shortly after parturition, there is a striking increase in energy production by fatty acid oxidation, due to the interrupted maternal glucose supply. At this time sufficient tissue carnitine levels are necessary for fatty acid oxidation in various tissues in the liver accompanied by ketone body production (33). Ketone bodies are important fuels for the surfactant precursor synthesis of the newborn. Therefore, treatment with a thyroxine-carnitine combination could also be of benefit in the early postnatal period for continuous surfactant synthesis. Although functional, rat lungs are still not mature at birth since they contain no true alveoli. Important morphological changes occur during the first 3 postnatal wk in the rat (24). These postnatal changes may constitute events affected by thyroid hormones (24).

Maternal carnitine-thyroxine treatment resulted in a significant $(p<0.01)$ increase of the short chain acylcarnitine content in fetal lungs, yet there was no increase in total carnitine content. This could be explained either by a possible increase of the fatty acid oxidation (mitochondrial or peroxisomal) induced by the thyroid hormone in the fetus that is accompanied by an increase of short chain acylcarnitine or possibly an enhanced generation of short chain acylcarnitine occurring in the placenta. In this case the source of the high short chain acylcarnitine levels found in the fetal rat lungs would be the placenta, and the fetus received short chain acylcarnitine instead of the free carnitine administered maternally.

The present animal experiments demonstrate that carnitine potentiates the effects of thyroxine on DPPC content of fetal rat lungs, and they support the concept of an interrelationship between carnitine and thyroxine metabolism. Obviously there are specific effects of a carnitine-thyroxine combination compared with the effects of carnitine or thyroxine treatment. In a former study we showed that carnitine potentiated the effects of betamethasone on DPPC content of fetal rat lungs (7). Therefore, treatment with a carnitine combination may be of more benefit decreasing the incidence of respiratory distress syndrome than the administration of thyroxine (or betamethasone) alone.

Acknowledgement The authors thank Barbara Lohninger for technical assistance and typing the paper.

\section{REFERENCES}

1. Collaborative group on antenatal steroid therapy 1981 Effect of antenatal dexamethasone administration on the prevention of respiratory distress syndrome. Am J Obstet Gynecol 141:276-298

2. Rooney SA 1985 The surfactant system and lung phospholipid biochemistry. Am Rev Respir Dis 131:439-460

3. Rooney SA, Motoyama EK 1977 Biochemical studies on normal and hormoneaccelerated development of pulmonary surfactant. In: Schneider RP. Dagle GE. Ragan HA (eds) Pulmonary Macrophage and Epithelial Cells, Proceedings of the 16th Annual Hanford Biology Symposium. Energy Research and
Development Administration, Springfield, VA, pp 162-180

4. Wu B, Kikkawa Y, Orzalesi MM, Motoyama EK, Kaibara M, Zigas CJ, Cook $\mathrm{CD} 1973$ The effect of thyroxine on the maturation of fetal rabbit lungs. Biol Neonate 22:161-166

5. Gross I, Dynia DW, Wilson CM, Ingleson LD, Gewolb IH, Rooney SA 1984 Glucocorticoid-thyroid hormone interactions in fetal rat lung. Pediatr Res 18:191-196

6. Lohninger A, Krieglsteiner HP, Nikiforov A, Erhardt W, Specker M, Martin $\mathrm{G}$, Kaiser $\mathrm{E} 1984$ Comparison of the effects of betamethasone and $\mathrm{L}$-carnitine on dipalmitoyl phosphatidylcholine content and phosphatidylcholine species composition in fetal rat lungs. Pediatr Res 18: 1246-1252

7. Lohninger A, Krieglsteiner HP, Salzer H, Riedl W, Erhardt W, VytiskaBinsdorfer E 1986 Studies on the effects of betamethasone, L-carnitine, and betamethasone-L-carnitine combinations on dipalmitoyl phosphatidylcholine content and phosphatidyicholine species composition in fetal rat lungs. J Clin Chem Clin Biochem 24:361-368

8. Bremer J 1983 Carnitine-metabolism and function. Physiol Rev 63:14201480

9. Cederblad G, Engstrøm G 1978 Effect of thyroxine treatment on carnitine levels in mice. Acta Pharmacol Toxicol 43:1-13

10. Hoppel CL, Brady L 1985 Carnitine palmitoyltransferase and transport of fatty acids. In: Martinosi AN (ed) The Enzymes of Biological Membranes. Plenum, New York, pp 139-175

11. Folch J, Lees M, Stanley GH 1957 A simple method for the isolation and purification of the total lipids from animal tissue. J Biol Chem 225:497-503

12. Lohninger A, Nikiforov A 1980 A quantitative determination of natural dipalmitoyl lecithin with dimyristoyl lecithin as internal standard by capillary gas-liquid chromatography. J Chromatogr 192:185-192

13. Cederblad G, Lindstedt S 1972 A method for the determination of carnitine in the picomole range. Clin Chim Acta 37:235-240

14. Christiansen RZ, Bremer J 1978 Acetylation of Tris and Tris derivatives by carnitine acetyltransferase. FEBS Lett 86:99-102

15. Cederblad G, Finnström O, Martensson J 1982 Urinary excretion of carnitine and its derivatives in newborns. Biochem Med 27:260-265

16. Dunnet CW 1964. New tables for multiple comparisons with a control. Biometrics 20:482-485

17. Weinhold PA, Quade MM, Brozowski TB, Feldman DA 1980 Increased synthesis of phosphatidylcholine by rat lung following premature birth. Biochim Biophys Acta 617:76-84

18. Cuestas RA, Lindall A, Engel RR 1976 Low thyroid hormones and respiratory distress syndrome of the newborn. Studies on cord blood. N Engl J Med 295:297-307

19. Dhanireddy R, Smith YF, Hamosh M, Mullon DK, Scanlon JW, Hamosh P 1983 Respiratory distress syndrome in the newborn: relationship to serum prolactin, thyroxine and sex. Biol Neonate 43:9-15

20. Ho Yuen B, Phillips WDP, Cannon W, Sy L, Redford D, Burch P 1982 Prolactin, estradiol, and thyroid hormones in umbilical cord blood of neonates with and without hyaline membrane disease: a study of 405 neonates from midpregnancy to term. Am J Obstet Gynecol 142:698-703

21. Roti E, Fang SL, Green K, Emerson CH, Braverman LE 1981 Human placenta is an active site of thyroxine and 3,5-triiodothyronine tyrosyl ring deiodination. J Clin Endocrinol Metabol 53:498-501

22. Roti E, Fang SL, Braverman LE, Emerson CH 1982 Rat placenta is an active site of inner ring deiodination of thyroxine and 3-triiodothyronine. Endocrinology 1 10:34-37

23. Dussault $\mathrm{JH}$, Coulombe $P 1980 \mathrm{Minimal}$ placental transfer of L-thyroxine $\left(\mathrm{T}_{4}\right)$ in the rat. Pediatr Res 14:228-231

24. Ruel J, Coulombe P, Dussault JH 1982 Characterization of nuclear 3,5,3' triiodothyronine receptors in the developing rat lung: effects of hypo- and hyperthyroidism. Pediatr Res 16:238-242

25. Gonzales LW, Ballard PL 1981 Identification and characterization of nuclear 3,5,3'-triiodothyronine-binding sites in fetal human lung. $\mathbf{J}$ Clin Endocrinol Metab 53:21-28

26. Hahn P 1981 The development of carnitine synthesis from $\gamma$-butyrobetaine in the rat. Life Sci 29:1057-1060

27. Borum P 1978 Variation in tissue carnitine concentrations with age and sex in the rat. Biochem J 176:677-681

28. Seccombe D, Hahn P, Novak M 1978 The effect of diet and development on blood levels of free and esterified carnitine in the rat. Biochim Biophys Acta 528:483-489

29. Borum P 1981 Possible carnitine requirements of the newborn and the effect of genetic disease on the carnitine requirement. Nutr Rev 39:385-390

30. Hahn P, Novak M 1985 How important are carnitine and ketones for the newborn infant? Fed Proc 44:2369-2373

31: Gilfillan AM, Chu AJ, Smart DA, Rooney SA 1983 Single plate separation of lung phospholipids including disaturated phosphatidylcholine. J Lipid Res 24:1651-1656

32. Mason RJ, Williams MC 1980 Phospholipid composition and ultrastructure of A549 cells and other cultured pulmonary epithelial cells of presumed type II cell origin. Biochim Biophys Acta 617:36-42

33. Novak M, Penn-Walker D, Hahn P, Monkus EF 1975 Effect of carnitine on lipolysis in subcutaneous adipose tissue of newborns. Biol Neonate 25:8595 